\title{
Stimulus similarity and encoding time influence incidental recognition memory in adult monkeys with selective hippocampal lesions
}

\author{
Alyson Zeamer, ${ }^{1,3,5}$ Martine Meunier, ${ }^{2}$ and Jocelyne Bachevalier ${ }^{1,4}$ \\ ${ }^{1}$ University of Texas Health Science Center, Houston, Texas 77030, USA; ${ }^{2}$ Espace et Action, INSERM U864 \& Université Claude Bernard \\ Lyon 1, Bron, France
}

\begin{abstract}
Recognition memory impairment after selective hippocampal lesions in monkeys is more profound when measured with visual paired-comparison (VPC) than with delayed nonmatching-to-sample (DNMS). To clarify this issue, we assessed the impact of stimuli similarity and encoding duration on the VPC performance in monkeys with hippocampal lesions and sham-operated controls. The novelty preference was compared for pictures of dissimilar vs. similar objects and for encoding duration of 30, 10, 5, and $1 \mathrm{sec}$. The novelty preference was spared after hippocampal lesions with dissimilar (colored or black and white [BW]) stimuli and an encoding time $\geq 10 \mathrm{sec}$, but declined with similar stimuli or a short encoding time of 1 or $5 \mathrm{sec}$. Therefore, the severe VPC impairment reported earlier after hippocampal damage cannot be attributed to the long encoding time used $(30 \mathrm{sec})$ relative to DNMS (1-5 sec). However, it may result, at least in part, from the poorer distinctiveness of the stimuli typically used for VPC (BW slides of pictures of equal size and brightness of objects differing in shape) relative to the actual objects used for DNMS, differing in shape, color, size, brightness, and texture. This conclusion fits well with current models that view the hippocampus as a comparator capable of individualizing the representations of highly overlapping inputs.
\end{abstract}

\section{Introduction}

To clarify the much debated role of the hippocampus in visual recognition memory, a crucial step is to understand why recognition memory impairment in monkeys and humans with selective hippocampal damage varies across tasks. In monkeys, visual paired comparison (VPC) revealed severe deficits at delays of $60 \mathrm{sec}$ or longer (Zola et al. 2000; Nemanic et al. 2004), whereas delayed nonmatching-to-sample (DNMS) revealed no deficit (Murray and Mishkin 1998; Nemanic et al. 2004) or mild deficits at delays of 10 min and beyond (Beason-Held et al. 1999; Zola et al. 2000). A similar discrepancy was reported in humans (Pascalis et al. 2004). Although both tasks measure a monkey's ability to determine which, among two stimuli, has not been presented moments earlier, they present with major differences. The most obvious one is that VPC assesses incidental recognition, inferred from the time animals spend passively looking at pictures, whereas DNMS taxes intentional recognition, actively expressed by a reward-driven selection of objects. Compensatory effortful processes could therefore explain DNMS sparing after hippocampal lesions. However, an earlier attempt to prove this hypothesis yielded unconvincing results. Distracting lesioned monkeys with a motor task or context change during DNMS delays did yield a deficit at 10 min-delays, but it had no effect at the 60- and 120-sec delays that elicited a robust VPC impairment (Nemanic et al. 2004).

We therefore explored two other major differences between VPC and DNMS that have so far been overlooked. One concerns

Present addresses: ${ }^{3}$ Thomas Jefferson University, Philadelphia, PA 19107, USA; ${ }^{4}$ Emory University, Atlanta, GA 30329, USA. ${ }^{5}$ Corresponding author.

E-mail azeamer@yahoo.com; fax (215) 923-3808.

Article is online at http://www.learnmem.org/cgi/doi/10.1101//m.2076811. the stimuli and the other the duration of encoding. First, all DNMS studies used colorful actual objects as stimuli, whereas both VPC studies used black and white pictures of objects (Nemanic et al. 2004) or line drawings (Zola et al. 2000) displayed with the poor resolution afforded by slide projection. Thus, the ambiguity of VPC stimuli created by their similarity and their coarse display could explain VPC's greater sensitivity to hippocampal damage in monkeys. Second, the length of encoding is clearly different in the two tasks. In VPC, familiarization is pursued until the animal has cumulated $25 \mathrm{sec}$ (Zola et al. 2000) or $30 \mathrm{sec}$ (Nemanic et al. 2004) of looking at the sample item. By contrast, in DNMS, the opaque screen is raised for just as long as it takes the animal to displace the sample object and retrieve the food reward underneath, thereby allowing sometimes as little as $1 \mathrm{sec}$ and seldom more than $5 \mathrm{sec}$ for encoding. However counterintuitive, the possibility that longer familiarization leads to more robust recognition impairment after hippocampal lesions cannot be ruled out.

To explore these two issues, three monkeys with neurotoxic hippocampal lesions and three sham-operated controls were submitted to a new computer version of VPC optimizing stimuli display. In a basic VPC trial, a picture was presented for view for a given cumulative familiarization time $(30,10,5$, and $1 \mathrm{sec})$ and after varying delays $(10,30,60$, and $120 \mathrm{sec})$, the familiar picture was represented side-by-side with a novel picture for a 5-sec retention test, followed 5 sec later by a second 5 -sec retention test where the left/right position of the familiar and novel pictures was inverted. First, the impact of stimuli similarity was assessed by comparing novelty preference for pairs of pictures, either colored (as in DNMS) or black and white (as typical for VPC), of distinct objects vs. for pairs of black and white pictures of similar objects (Fig. 1). Then, the importance of encoding time was assessed by reducing familiarization first to $10 \mathrm{sec}$, and 
A Color



B BW

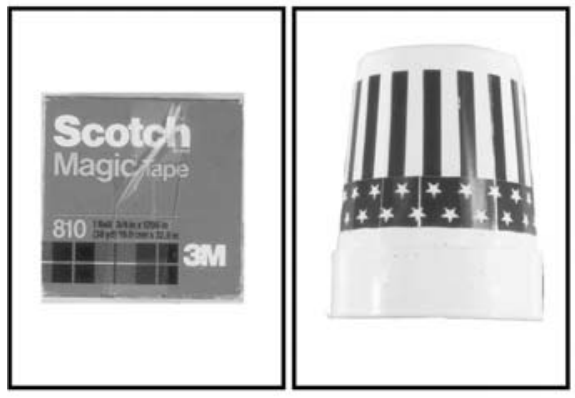

C BW-OF

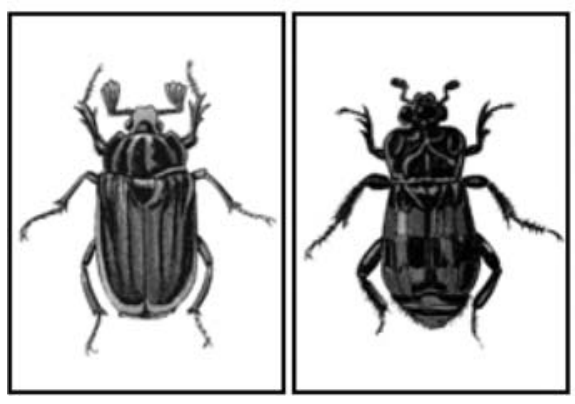

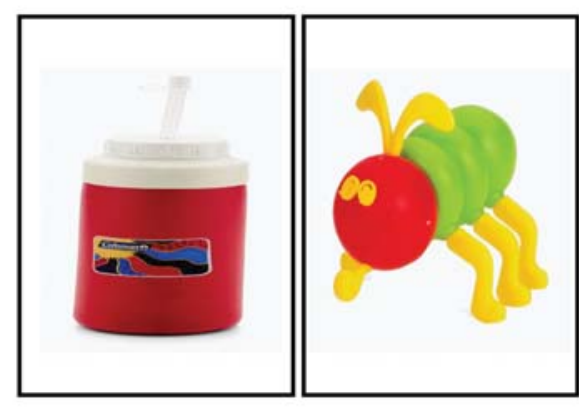
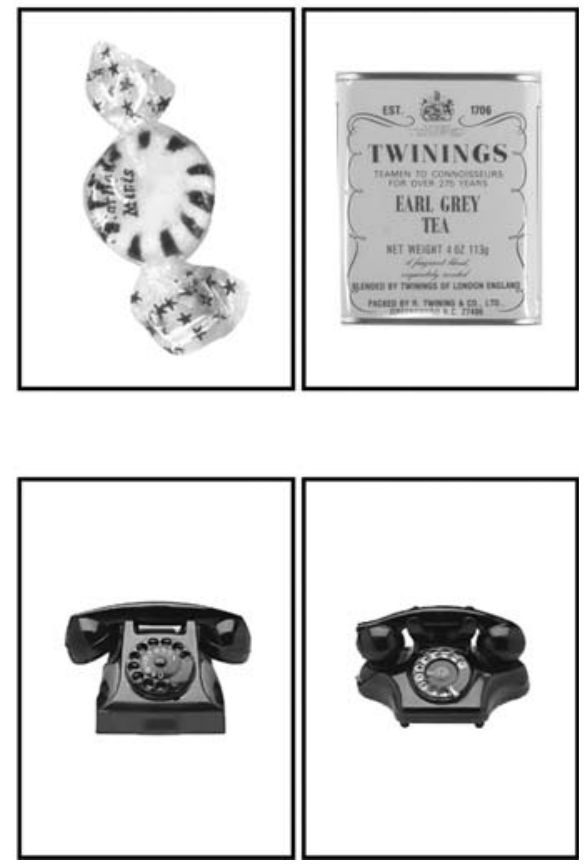

Figure 1. Representative examples of the three types of stimulus pairs used to test novelty preference. Pictures were deliberately paired so that objects were either very dissimilar, either colored $(A)$ or black and white $(B)$ or, on the contrary, highly similar $(C)$.

then to $5 \mathrm{sec}$, and $1 \mathrm{sec}$, i.e., values approximating those occurring in DNMS.

\section{Results}

\section{Evaluation of hippocampal lesions}

Lesion extent was evaluated using neuroimaging procedures described by Nemanic and colleagues (2002) for all three animals of the group and a histological evaluation of the lesion was available for one animal (H-ibo-9). The percent of damage to the hippocampal formation and adjacent cortical areas (unintended damage) in both the left and right hemispheres as derived from the MR images is shown in Table 1. In all cases but one (case H-ibo-7), the hippocampal damage was extensive and bilateral (see Figs. 2, 3; Alvarado et al. 2010).

In case $\mathrm{H}-\mathrm{ibo}-7$, the lesion of the hippocampal formation was asymmetrical with more extensive damage on the right $(58.6 \%)$ than on the left $(12.7 \%)$. The percent damage to the left hippocampal formation remained minimal despite the use of a second surgical procedure to target the spared hippocampal tissue. However, as shown in Figure 2, the small damage on the left side included most of the CA1 field and portions of the CA2 field, most likely disrupting the integrity of the trisynaptic circuit, as well as the direct pathway from the entorhinal cortex to CA1. On the right, damage began at the pes hippocampus and remained largely complete along the anterior half of the hippocampal formation (see Fig. 2, levels +13 to +7 ). For the caudal-half portion (see Fig. 2 , levels +4 to -2 ), the hippocampal damage included only small portions of the CA1, CA2, and CA3 fields. The only minimal extra damage (11\%) was located in the right amygdala.

In case $\mathrm{H}$-ibo-8, the lesion of the hippocampal formation was extensive (Fig. 2; Table 1) with more damage on the right $(98.2 \%)$ than on the left (79.8\%), and included all CA fields, dentate gyrus, and subiculum. Sparing was located in the caudal-most portion of the hippocampal formation. The lesion in this case was restricted to the hippocampal formation and no damage to adjacent structures was noticed.

In case H-ibo-9, based on the FLAIR images and histological sections (see Figs. 2, 3, left, middle columns), the lesion of the hippocampal formation was extensive and symmetrical $(91.0 \%$ 
Table 1. Percent of intended and unintended damage

\begin{tabular}{|c|c|c|c|c|c|c|c|c|c|c|c|c|c|c|c|c|}
\hline \multirow[b]{2}{*}{ Cases } & \multicolumn{4}{|c|}{ Hippocampal formation } & \multicolumn{4}{|c|}{ Amygdala } & \multicolumn{4}{|c|}{ ERh } & \multicolumn{4}{|c|}{ TF } \\
\hline & $L$ & $R$ & $x$ & $w$ & $L$ & $R$ & $x$ & $w$ & $L$ & $R$ & $x$ & $w$ & $L$ & $R$ & $x$ & $w$ \\
\hline -ibo-7 & 12.7 & 58.6 & 35 & 7 & 0 & 11.0 & 5.5 & 0 & 0 & 0 & 0 & 0 & 0 & 0 & 0 & 0 \\
\hline Hibo- & 79.8 & 98 & $88-v-v-v-1$ & 78 & 0 & 0 & 0 & 0 & 0 & 0 & v & 0 & 0 & 0 & 0 & \\
\hline H-ibo-9 & 91.0 & 89.4 & 90.2 & 81.3 & 12.9 & 1.0 & 6.9 & 0.1 & 0.7 & 0.6 & 0.7 & 0 & 0.9 & 1.3 & 1.1 & 0 \\
\hline  & 61.2 & 82.3 & 71.7 & 55.8 & 4.3 & 4.0 & 4.1 & 0 & 0.2 & 0.2 & 0.2 & 0 & 0.3 & 0.4 & 0.4 & 0 \\
\hline
\end{tabular}

Percent damage to the hippocampal formation for the three subjects in Group $\mathrm{H}$-ibo as estimated from preand post-surgery coronal MR images: $L$, percent damage to the left hemisphere; $R$, percent damage to the right hemisphere; $X$, average damage to both hemispheres; $W$, weighted average damage to both hemispheres $(W=(L \times R) / 100)$; ERh, entorhinal cortex; and TF: cytoarchitectonic fields of the parahippocampal gyrus as defined by von Bonin and Bailey (1947).

on the left and $89.4 \%$ on the right, see Table 1), including all CA fields, dentate gyrus, and subiculum along the entire length of the hippocampal formation on both sides. Sparing was restricted to the uncus, anteriorly (see Fig. 3, levels +11 bilaterally and +9 on the left) and to the caudal-most portion of the hippocampal formation. There was also mild bilateral damage to the tail of the caudate $(45.1 \%$ on the left and $15.0 \%$ on the right), most likely due either to leakage of the neurotoxin during penetration or retraction of the needles or to minor ischemic infarct.

\section{Looking behavior during the familiarization phase and retention tests}

During the familiarization phase, the total time needed to accumulate the required $30,10,5$, or $1 \mathrm{sec}$ of encoding did not differ across the two groups (all $P>$ 0.05). During the retention tests, all animals were found first to look longer at color stimuli than at BW ones after 30 sec of encoding (means across delays; dissimilar color stimuli: controls $=5.54 \mathrm{sec}$, $\mathrm{H}$-ibo $=6.62 \mathrm{sec}>$ dissimilar $\mathrm{BW}$ stimuli: controls $=4.04 \mathrm{sec}, \mathrm{H}-\mathrm{ibo}=4.63$ sec, and >similar stimuli: controls $=$ $4.12 \mathrm{sec}, \mathrm{H}$-ibo $=4.18 \mathrm{sec}$; paired $t$-tests, all $P<0.0001$ ) and then to look longer at dissimilar color and BW stimuli after $10 \mathrm{sec}$ of encoding, than after 5 or $1 \mathrm{sec}$ of encoding (controls: $6.0 \mathrm{sec}>3.3 \mathrm{sec}$ or $3.6 \mathrm{sec}$; H-ibo: $5.6 \mathrm{sec}>3.9 \mathrm{sec}$ or 4.1 sec; paired $t$-tests, all $P<0.05)$. As stimulus types and encoding times were tested successively, starting, respectively, with color stimuli and 10 sec-encoding, these differences may reflect a progressive reduction in looking time over testing rather than a true stimuli or encoding effect. Whatever the case, the important point here is that looking times during retention tests never differed across groups in any condition, that is, hippocampal damage did not produce a change in looking behavior that could explain the differences in novelty preference, described in the next paragraphs.

\section{Novelty preference for dissimilar color vs. BW stimuli}

Comparison of novelty preference for dissimilar color vs. BW stimuli (two groups $\times$ two stimuli $\times$ three delays ANOVA) yielded no reliable effects for any of the factors or their interactions
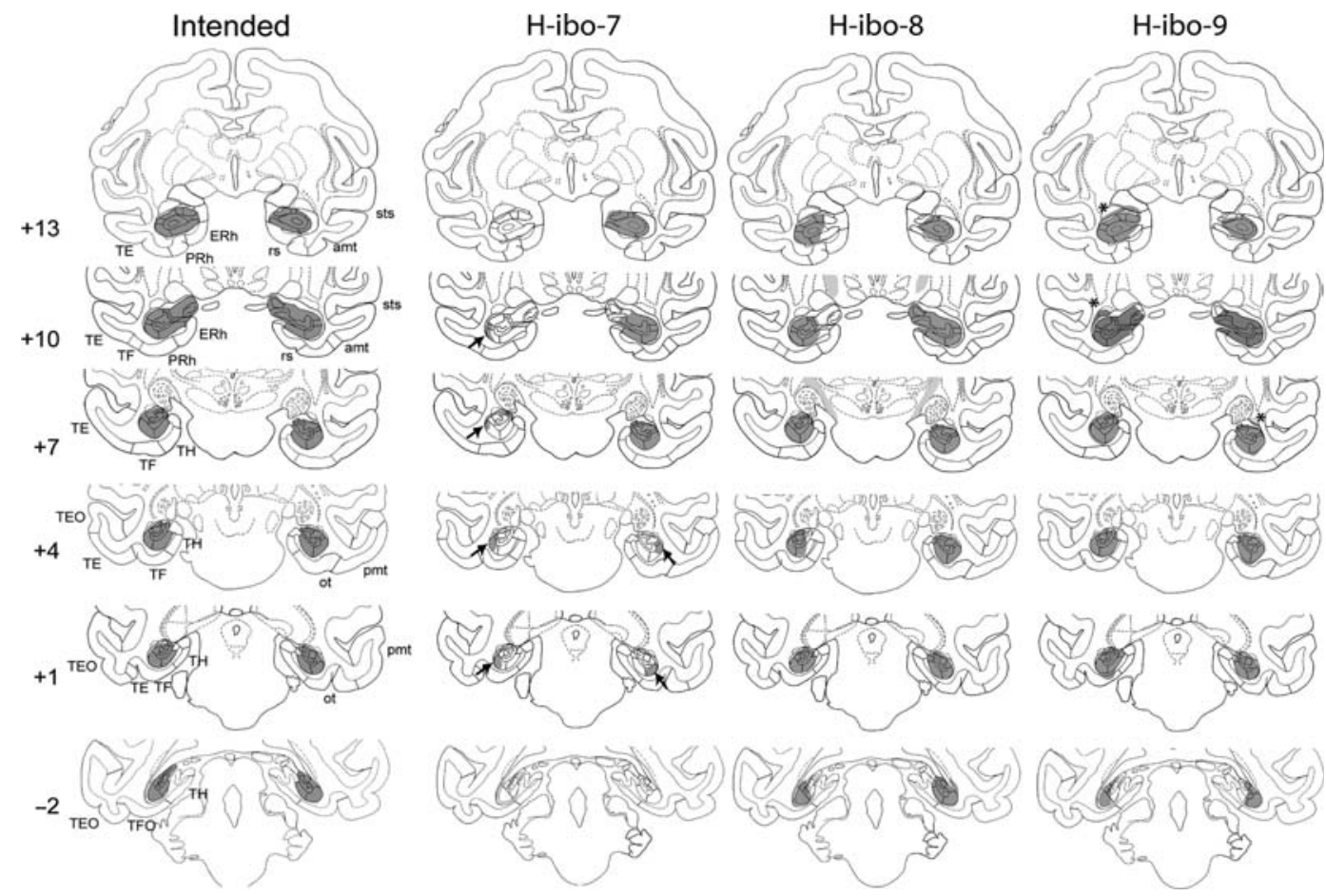

Figure 2. Coronal sections through the hippocampal formation of a macaque brain. Left column depicts in gray the intended lesions as reconstructed onto six anterior-posterior (top to bottom) levels. The numerals to the left of each coronal section indicate the distance in millimeters from the interaural plane. The remaining columns depict the extent of the lesions for cases H-ibo-7, -8, and -9, as estimated from T1 MR images and reconstructed onto sections of the macaque brain. Arrows point to damage to area CA1 of the hippocampus in case $\mathrm{H}$-ibo-7. An asterisk indicates extra damage in tail of caudate in case H-ibo-9. Abbreviations: amt, anterior middle temporal sulcus; ERh, entorhinal cortex; ot, occipitotemporal sulcus; PRh, perirhinal cortex; pmt, posterior middle temporal sulcus; rs, rhinal sulcus; sts, superior temporal sulcus; and TE, TF, and TH, cytoarchitectonic fields as described by von Bonin and Bailey (1947). 
1-Week Post Surgical FLAIR

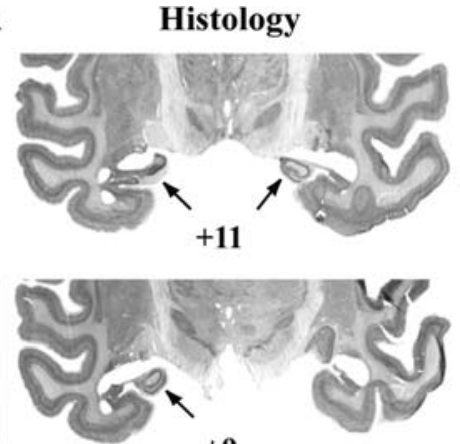

$+9$

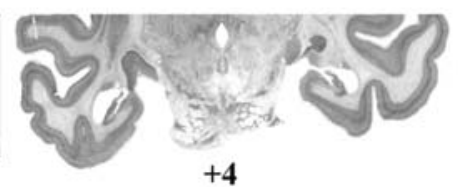

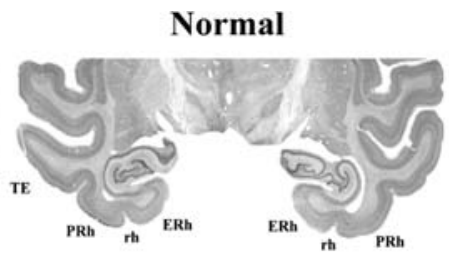


Figure 3. The left column illustrates the extent of hypersignals across three anterior-posterior levels of the hippocampus and the middle column shows the resulting cell loss on matched thionin-stained coronal sections of case $\mathrm{H}$-ibo- 9 . Note the asymmetry on the anterior-posterior axis between the left and right hemispheres on the photomicrographs (right being slightly more posterior than the left). Arrows point to sparing of the uncus bilaterally in this case. For comparison, the right column displays photomicrographs of matched coronal sections through the hippocampal formation of a normal control. An asterisk indicates damage caused from a needle during a tracer injection 2 wk prior to the removal of the brain. The numerals at the bottom of each coronal section indicate the distance in millimeters from the interaural plane.

(Table 2). Group scores over the three delays were similar for animals with hippocampal lesions and for controls. Performance remained above chance in each group at each delay (one-sample $t$-tests, all $P<0.04$ ) and showed no significant decline over delays.

In summary, these results demonstrate that a high-resolution display of 2D stimuli specifically selected to be highly dissimilar yields normal novelty preference in monkeys with selective hippocampal damage that withstands delays of up to $120 \mathrm{sec}$. This holds true whether stimuli are presented in their original colorful version or in a black and white version, converting colors into shades of gray, indicating that color is not a requisite to obtain normal VPC performance in hippocampal-operated monkeys.

\section{Novelty preference for dissimilar vs. similar stimuli}

Scores for dissimilar color and BW stimuli were averaged, and then compared to those obtained for similar stimuli using an ANOVA with three factors (two groups $\times$ two stimuli $\times$ three delays).

Table 2. Percent looking at novel object for dissimilar color (color) and black and white (BW) pictures after $30 \mathrm{sec}$ of encoding and with $10-120$-sec retention delays

\begin{tabular}{|c|c|c|c|c|c|c|c|c|}
\hline \multirow{2}{*}{$\begin{array}{l}\text { Stimuli } \\
\text { Delay }\end{array}$} & \multicolumn{4}{|c|}{ Dissimilar/color } & \multicolumn{4}{|c|}{ Dissimilar/BW } \\
\hline & $\begin{array}{c}10 \\
\text { sec }\end{array}$ & $\begin{array}{c}60 \\
\text { sec }\end{array}$ & $\begin{array}{l}120 \\
\text { sec }\end{array}$ & Mean & $\begin{array}{c}10 \\
\text { sec }\end{array}$ & $\begin{array}{l}60 \\
\text { sec }\end{array}$ & $\begin{array}{l}120 \\
\text { sec }\end{array}$ & Mean \\
\hline C-7 & 67.7 & 71.1 & 73.5 & 70.8 & 66.9 & 62.8 & 59.2 & 63.0 \\
\hline C-8 & 80.9 & 65.5 & 67.1 & 71.2 & 63.2 & 69.9 & 66.0 & 66.4 \\
\hline C-9 & 71.8 & 68.3 & 66.0 & 68.7 & 66.3 & 63.4 & 75.4 & 68.4 \\
\hline avg & 73.5 & 68.3 & 68.9 & 70.2 & 65.5 & 65.4 & 66.9 & 65.9 \\
\hline SEM & 3.9 & 1.6 & 2.3 & 0.8 & 1.1 & 2.3 & 4.7 & 1.6 \\
\hline H-ibo-7 & 69.8 & 64.6 & 68.3 & 67.6 & 64.5 & 69.8 & 68.0 & 67.4 \\
\hline H-ibo-8 & 78.8 & 73.2 & 78.1 & 76.7 & 69.3 & 62.8 & 61.6 & 64.6 \\
\hline H-ibo-9 & 75.8 & 69.8 & 77.6 & 74.4 & 63.4 & 75.0 & 67.4 & 68.6 \\
\hline avg & 74.8 & 69.2 & 74.7 & 72.9 & 65.7 & 69.2 & 65.7 & 66.9 \\
\hline SEM & 2.6 & 2.5 & 3.2 & 2.7 & 1.8 & 3.5 & 2.0 & 1.2 \\
\hline
\end{tabular}

Abbreviations: $\mathrm{C}$, sham-operated control animals; $\mathrm{H}$-ibo, monkeys with neurotoxic hippocampal lesions; mean, mean over the three delays; avg, average for each group; and SEM, standard error of the mean.

\section{Stimulus and group effects}

Introducing similar stimuli reduced novelty preference in both groups (stimulus: $\left.F_{(1,4)}=36.8, P=0.004\right]$ ) but this change affected animals with hippocampal lesions much more than it did in controls (group: $F_{(1,4)}=8.4, P=0.04$; stimulus $\times$ group: $F_{(1,4)}=9.4, P=0.04 ;$ Fig. 4A; Table 3$)$. Mean scores across delays exhibited a sharp $15 \%$ drop in the $\mathrm{H}$-ibo group (paired $t$-test, $P=0.04$ ), which contrasted with the marginal 5\% decrease observed in controls (paired $t$-test, $P=0.06$ ). For dissimilar stimuli, the $\mathrm{H}$-ibo group's scores averaged across color and BW stimuli were well above chance level (one-sample $t$-tests; $\mathrm{H}$-ibo: $P=0.002$; controls: $P=0.001$ ) and similar to controls. The pattern was different with similar stimuli for which the H-ibo group's scores dropped to a level barely, though significantly, superior to chance (one-sample $t$-tests; H-ibo: $P=0.05$, compared to controls: $P=$ 0.006), and markedly inferior to controls' performances (twosample $t$-test; $P=0.03$ ). Note that the deleterious effect of stimulus similarity on $\mathrm{H}$-ibo animals' performances held true even when color stimuli were removed from consideration. Indeed, stimulus $X$ group interaction was also observed when similar BW stimuli were compared to dissimilar BW stimuli $\left(F_{(1,4)}=\right.$ 1.21, $P=0.02)$.

\section{Delay effect}

The global ANOVA also revealed a delay effect (delay: $F_{\text {(HUYNH-FELDT: } 2,8)}=5.8, P=0.03$ ), but no significant interactions with the other two factors (Fig. 4B; Table 3). Separate ANOVAs (two groups $\times$ three delays) for each stimulus type demonstrated that the delay effect was reliable only for similar stimuli $\left(F_{\text {(HUYNH-FELDT: } 2,8)}=4.9, P=0.04\right)$ as compared to dissimilar stimuli ( $F_{\text {(HUYNH-FELDT: } 2,8)}=0.4, P=$ not significant). This delaydependent decline of novelty preference for similar stimuli was comparable in the two groups (delay $\times$ group interaction: $F_{\text {(HUYNH-FELDT: } 2,8)}=0.3, P=\mathrm{ns}$ ). The group difference remained stable across delays, amounting to about $8 \%$ at each delay (twosample $t$-tests; 10 sec: $P=0.06 ; 60$ sec: $P=0.02 ; 120$ sec: $P=$ 0.04). Finally, scores of controls for similar stimuli remained 

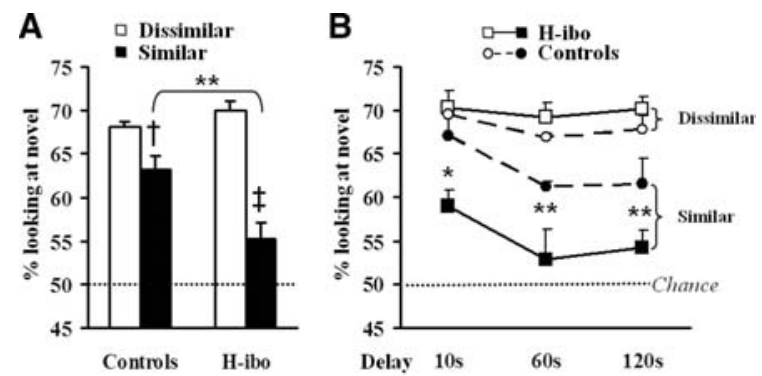

Figure 4. Novelty preference for dissimilar vs. similar stimuli obtained with a fixed encoding time of $30 \mathrm{sec}$. Percent of time spent looking at the novel stimulus (mean \pm SEM) in monkeys with sham operations (Controls) or neurotoxic hippocampal lesions ( $\mathrm{H}$-ibo) for pairs of dissimilar (white bars in $A$ and open symbols in $B$ ) vs. similar (black bars in $A$ and filled symbols in $B$ ) stimuli. ( $A$ ) Overall performance averaged across al delays. (B) Performance at each of the three delays tested. Symbols indicate within-group differences revealed by paired $t$-test $\left(A,{ }^{\dagger}, P=0.06\right.$ and $\left.{ }^{\ddagger}, P \leq 0.04\right)$ and between-group differences revealed by two-sample $t$-test $\left(A\right.$ and $B,{ }^{*}, P=0.06$ and $\left.{ }^{* *}, P \leq 0.04\right)$. All scores are different from chance level indicated by the dotted line (one-sample $t$-tests, all $P \leq$ 0.05), except those of $\mathrm{H}$-ibo animals for similar stimuli in $A$ and at 60 -sec delays in $B$. Each data point in $B$ represents 20 trials for dissimilar stimuli (10 color and $10 \mathrm{BW}$ ) and 10 trials for similar stimuli.

above chance at each delay (one-sample $t$-tests; 10 sec: $P=0.01$; 60 sec: $P=0.001 ; 120$ sec: $P=0.03)$, whereas those of the $\mathrm{H}$-ibo group fluctuated around chance levels (10 sec: $P=0.06$; 60 sec: $P=0.20 ; 120$ sec: $P=0.02$ ).

\section{Summary}

The results demonstrate that, even when using a high-resolution display, introducing 2D stimuli specifically selected to be highly similar disrupts VPC performance in monkeys with selective hippocampal damage. Similar stimuli markedly reduce novelty preference in operated monkeys, although without suppressing it entirely, and without exacerbating the delay-dependent decline already present in controls for delays up to $120 \mathrm{sec}$.

\section{Novelty preference when reducing the typical 30-sec encoding to 10,5 , and $1 \mathrm{sec}$}

Scores obtained with color and BW dissimilar stimuli and reduced encoding durations of 10,5 , and 1 sec were analyzed using a threefactor ANOVA (two groups $\times$ three encodings $\times$ three delays).

Table 3. Percent looking at novel object for pairs of dissimilar vs. similar stimuli after $30 \mathrm{sec}$ of encoding and with 10-120-sec retention delays

\begin{tabular}{|c|c|c|c|c|c|c|c|c|}
\hline \multirow{2}{*}{$\begin{array}{l}\text { Stimuli } \\
\text { Delay }\end{array}$} & \multicolumn{4}{|c|}{ Dissimilar } & \multicolumn{4}{|c|}{ Similar } \\
\hline & $\begin{array}{c}10 \\
\text { sec }\end{array}$ & $\begin{array}{l}60 \\
\text { sec }\end{array}$ & $\begin{array}{l}120 \\
\text { sec }\end{array}$ & Mean & $\begin{array}{c}10 \\
\text { sec }\end{array}$ & $\begin{array}{l}60 \\
\text { sec }\end{array}$ & $\begin{array}{l}120 \\
\text { sec }\end{array}$ & Mean \\
\hline$C-7$ & 67.3 & 67.0 & 66.4 & 66.9 & 62.7 & 60.6 & 61.5 & 61.6 \\
\hline C-8 & 72.1 & 67.7 & 66.6 & 68.8 & 71.3 & 60.8 & 66.7 & 66.3 \\
\hline C-9 & 69.1 & 65.9 & 70.7 & 68.5 & 67.0 & 62.4 & 56.4 & 61.9 \\
\hline avg & 69.5 & 66.8 & 67.9 & 68.1 & 67.0 & 61.3 & 61.5 & 63.3 \\
\hline SEM & 1.4 & 0.5 & 1.4 & 0.6 & 2.5 & 0.6 & 3.0 & 1.5 \\
\hline H-ibo-7 & 67.2 & 67.2 & 68.2 & 67.5 & 65.5 & 57.6 & 53.4 & 58.8 \\
\hline H-ibo-8 & 74.1 & 68.0 & 69.9 & 70.6 & 56.9 & 48.9 & 53.0 & 52.9 \\
\hline H-ibo-9 & 69.6 & 72.4 & 72.5 & 71.5 & 54.6 & 51.9 & 56.0 & 54.2 \\
\hline avg & 70.3 & 69.2 & 70.2 & 69.9 & 59.0 & 52.8 & 54.1 & 55.3 \\
\hline SEM & 2.0 & 1.6 & 1.3 & 1.2 & 3.3 & 2.6 & 0.9 & 1.8 \\
\hline
\end{tabular}

Dissimilar scores are the average of color and BW scores reported in Table 2. Abbreviations as in Table 2.

\section{Encoding and group effects}

The global ANOVA revealed a different encoding effect across groups (group: $F_{(1,4)}=7.8, P=0.05$; encoding: $F_{(\text {HUYNH-FELDT: }}$ $2,8)=4.8, P=0.04$; encoding $\times$ group: $F_{(\text {HUYNH-FELDT: } 2,8)}=7.9$, $P=0.01$; Fig. 5A; Table 4). This group difference did not emerge with the 10-sec encoding time, which yielded the same pattern as the typical 30-sec encoding time (see Fig. 4A). Namely, H-ibo animals' scores were well above chance (one-sample $t$-tests; H-ibo: $P=0.004$; controls: $P=0.02$ ). It took the 5 - and 1 -sec encoding times to reveal the effect of hippocampal damage. The performance of $\mathrm{H}$-ibo animals dropped by about $7 \%$ when encoding was reduced from 10 to $5 \mathrm{sec}$ (paired $t$-test, $P=0.04$ ), and by about $13 \%$ when encoding was reduced from 10 to $1 \mathrm{sec}$ (paired $t$-test, $P=0.004)$. Hippocampal damage significantly reduced novelty preference after $5 \mathrm{sec}$ of encoding (H-ibo; one-sample $t$-test relative to chance: $P=0.004$; two-sample $t$-test relative to controls: $P=0.002$ ), whereas it abolished it after 1 sec of encoding (one-sample $t$-test relative to chance: $P=\mathrm{ns}$; two-sample $t$-test relative to controls: $P=0.04$ ).

\section{Delay effect}

The global ANOVA revealed a different encoding effect across delays $\left(F_{\text {(HUYNH-FELDT: }} 2,8\right)=7.8, \quad P=0.02$; encoding $\times$ delay: $F_{\text {(HUYNH-FELDT: } 4,16)}=3.0, P=0.05$ ), as both groups expectedly displayed their poorest performance for the 1-sec encoding120-sec delay combination (Fig. 5B; Table 4). More importantly, however, none of the encoding times yielded a reliable delay $x$ group interaction. After $5 \mathrm{sec}$ of encoding, the difference in novelty preference between $\mathrm{H}$-ibo and control animals remained stable at around $8 \%$ throughout the three delays tested (two-sample $t$-tests; 30 sec: $P=0.008 ; 60$ sec: $P=0.009 ; 120$ sec: $P=0.005$ ). After 1 sec of encoding, the difference between the two groups varied from $5 \%$ at 30 sec to $13 \%$ at 60 and $120 \mathrm{sec}$ (two-sample $t$-tests; 60 sec: $P=0.05,120$ sec: $P=0.01)]$ but this delay-dependent decline failed to reach significance.

\section{Summary}

The results demonstrate that encoding time is of crucial importance for monkeys with selective hippocampal lesions. After 10 sec of encoding, hippocampal-operated monkeys show the same normal to slightly enhanced novelty preference as they do after the classical 30-sec encoding. However, when encoding time more closely approximates the brief exposures routinely occurring in DNMS, a deficit does emerge. Moderately impaired after 5 sec of encoding, novelty preference becomes severely impaired after $1 \mathrm{sec}$ of encoding. Like the deficit described previously for similar stimuli and long exposure, the impairment elicited by DNMS-like encoding times is not delay-dependent for delays up to $120 \mathrm{sec}$.

\section{Lesion extent and VPC performance}

Hippocampal damage was extensive and bilateral in cases $\mathrm{H}$-ibo-8 and -9 , involving $89 \%-90 \%$ of the hippocampal formation, whereas it was moderate and asymmetrical in case $\mathrm{H}$-ibo 7, involving most of the CA1 bilaterally, but only $36 \%$ of the total structure (Table 1). It is therefore important to note that careful examination of individual scores (Tables 2-4) revealed no major behavioral difference among the three animals. This observation is consistent with the lack of correlation between lesion extent and VPC scores reported in the four previous $\mathrm{H}$-ibo cases studied by Nemanic et al. (2004). Only one minor difference could be noted in the present animals. When impaired, case $\mathrm{H}$-ibo 7 tended to display a delay-dependent decline (see similar stimuli in Table 3, and 5- or 1-sec encoding in Table 4), that was not detectable in the other two cases. Spared hippocampal tissue may thus 
A

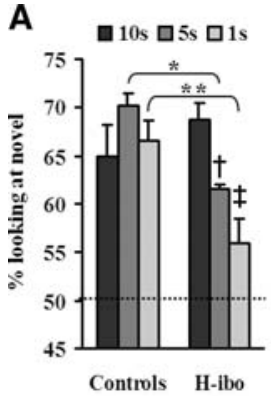

B

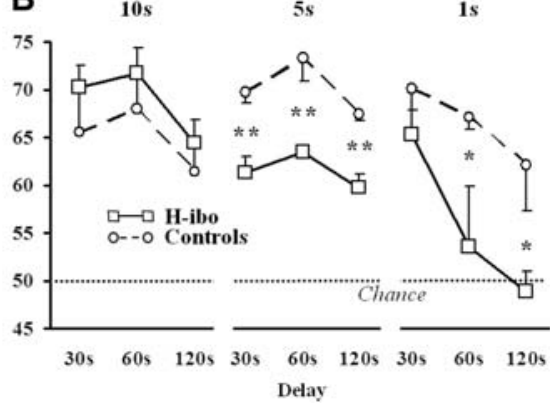

Figure 5. Novelty preference with encoding times of 10,5, and $1 \mathrm{sec}$. Percent of time spent looking at the novel stimulus (mean \pm SEM) for each of the three durations of encoding tested. $(A)$ Overall performance averaged across all delays. (B) Performance at each delay. Symbols indicate within-group differences $\left({ }^{\dagger}, P \leq 0.05\right.$ and $\left.{ }^{\ddagger}, P<0.01\right)$ or between-group differences $\left({ }^{*}, P \leq 0.05\right.$ and $\left.{ }^{* *}, P<0.01\right)$; other conventions as in Figure 4. Controls' scores approach chance level solely for the 1-sec encoding at the 120 -sec delay in $B$ (one-sample $t$-test, $P=0.06$ ). $\mathrm{H}$-ibo animals' scores are no greater than chance for overall performance with 1 -sec encoding in $A$, and for $1=$ sec encoding at 60 - and 120 -sec delays (all other $P<0.05$ ) in $B$. All data points shown in $B$ represent 10 trials with dissimilar stimuli (five color and five BW).

have sustained VPC performance at short delays in this animal. Except for this minor point, all the conclusions stated in the previous paragraphs hold true for all three animals.

\section{Discussion}

The present study is the first to show that, in monkeys with neurotoxic hippocampal lesions, novelty preference measured by VPC can be normal to weakened or fully disrupted, depending on stimuli similarity and encoding duration. Each of these two factors will be discussed in turn before describing how the present findings narrow the gap between VPC and DNMS that has heretofore plagued both the monkey and human literature on hippocampal damage, and how they fit in the current theoretical debate on hippocampal functions.

\section{Stimulus similarity in VPC}

Stimulus distinctiveness was increased here compared to earlier monkey studies by (1) using a computerized high-resolution display of pictures and (2) deliberately pairing familiar items with highly distinct novel ones. This combination provided the first demonstration of intact VPC performance in monkeys with selective hippocampal lesions. The sparing was evident for all dissimilar stimuli, whether presented in a color or BW version.

Introducing stimuli to be highly similar yielded only a marginal 5\% decline of novelty preference in sham-operated controls, but produced a sharp 15\% drop of novelty preference in $\mathrm{H}$-ibo monkeys at each delay tested (up to $120 \mathrm{sec}$ ). This finding has now been replicated after neonatal neurotoxic lesions of the hippocampus. As juveniles, monkeys with such early hippocampal damage display a VPC impairment with dissimilar stimuli (Zeamer et al. 2010) but, when adults, their deficit is strictly limited, as in the present animals, to similar stimuli (A Zeamer and $\mathrm{J}$ Bachevalier, unpubl.).

The present sparing of VPC performance at 60- and 120-sec delays with dissimilar BW stimuli stands in apparent contradiction with the chance-level performance reported at the same delays in Nemanic et al. (2004), also with BW stimuli. Two reasons can account for this unexpected difference. In the earlier four animals, hippocampal lesions encompassed $20 \%-64 \%$ of the hippocampal formation, that is, about as much as in present case H-ibo-7 (36\%), but less than in cases H-ibo-8 and -9 (89\% and $90 \%$ ). Could more complete hippocampal damage yield better VPC performance as proposed earlier for DNMS performance (Bachevalier and Meunier 1996; Mumby et al. 1996; Baxter and Murray 2001)? This possibility cannot be ruled out; yet, in the total of seven animals tested, we found no correlation between VPC performance and lesion extent to substantiate it. Alternatively, in light of the present findings, which reveal the crucial importance of stimulus similarity on the outcome of hippocampal damage, procedural variations could explain the deficit previously observed. Our earlier study used BW slides of objects that differed from the present dissimilar BW stimuli in two respects. First, they were presented with the low-resolution afforded by slide projection rather than with the present highresolution computer display. Second, at the same time, emphasis was not put on distinctiveness when pairing familiar and novel stimuli, but rather on maintaining equal size and brightness. These might have sufficed to reduce stimuli distinctiveness enough to disrupt recognition at long 60- and 120-sec delays in animals with hippocampal lesions.

In any case, the present results demonstrate that the effects of selective hippocampal lesions on recognition memory as assessed by VPC critically depend on stimuli distinctiveness. This conclusion converges with evidence gathered in rodents and humans. After infusion of AP5 (an NMDA antagonist) or naloxone (a $\mu$ opiate antagonist) into the CA3 field, rodents fail to detect novelty when novel items differ in only one element from familiar items (Hunsaker et al. 2007). Likewise, in humans, Yes/ No recognition is impaired in amnesic patients with selective hippocampal damage (Holdstock et al. 2002) and novelty signals occur in the hippocampus of healthy subjects only when novel items share some similarities with familiar ones (Pihlajamaki et al. 2004; Kirwan and Stark 2007; Bakker et al. 2008; Kumaran and Maguire 2009).

\section{Encoding time in VPC}

In control monkeys, incidental recognition of dissimilar stimuli showed a slight
Stimuli were dissimilar pairs of color or BW pictures, all different from those used for the data presented in Table 2. Other abbreviations as in Table 2. 
decline with encoding duration, from $68 \%$ after the classical 30 -sec encoding to $66 \%$ after 1 -sec encoding. In H-ibo animals, novelty preference was much more affected by variations of encoding time. Normal after long exposures of either $30 \mathrm{sec}$ (70\%) or $10 \mathrm{sec}(69 \%)$, novelty preference became moderately impaired after $5 \mathrm{sec}$ of encoding (62\%), and severely impaired after $1 \mathrm{sec}$ of encoding (56\%). As after long exposure to similar stimuli, $\mathrm{H}$-ibo animals seemed to have the same level of difficulty at all delays. The decrease of novelty preference when encoding time decreases has, to our knowledge, not been tested in humans with selective hippocampal damage, but it was reported in rodents with hippocampal lesions (Ainge et al. 2006).

That novelty preference measured by VPC critically depends in healthy subjects on the length of time provided for encoding the familiar stimulus has recently been demonstrated in adult humans (Richmond et al. 2004). Furthermore, both encoding time and stimulus complexity are critical factors that influence the emergence of novelty preference during infancy. Thus, older infants need less familiarization time than younger infants to achieve comparable novelty preference performance (Fagan 1974; Hunter et al. 1982; Rose et al. 1982; Rose 1983; Gunderson and Swartz 1986; Colombo et al. 1988; Richards 1997), and they also prefer more complex stimuli (e.g., patterns of greater number of elements or more angles) than younger infants (Brennan et al. 1966; Karmel 1969; Fantz et al. 1975). The interplay between stimulus complexity, familiarization time, and age on incidental recognition memory has also been demonstrated by Fagan (1974) and Hunter et al. (1983), showing major improvement in recognition memory during the first year of life in human infants that, interestingly, coincides with significant structural remodeling of the hippocampus during this period of development (for review, see Seress and Abraham 2008).

\section{VPC vs. DNMS: Narrowing the gap}

To date, three studies have directly compared VPC and DNMS (or DMS) in the same subjects with hippocampal damage, two in monkeys (Zola et al. 2000; Nemanic et al. 2004) and one in humans (Pascalis et al. 2004). All three reported greater sensitivity of VPC to hippocampal damage. The specific delays yielding severe VPC impairment varied across studies: $\geq 60 \mathrm{sec}$ in Nemanic et al. (2004), $\geq 10 \mathrm{sec}$ in Zola et al. (2000) (group RF2), and $\geq 5 \mathrm{sec}$ in patient YR studied by Pascalis et al. (2004). Yet, in all cases, DNMS or DMS performance at the same delays were found to be spared in the very same subjects. In monkeys, 10-min delays were necessary for a clear-cut DNMS deficit to emerge and patient YR's DMS performance remained perfect at all delays tested $(0-10 \mathrm{sec})$.

Monkey studies all used BW pictures matched for size and brightness for VPC, while using actual objects differing in many respects, including color, for DNMS. Likewise, Pascalis et al. (2004) used slide-projected BW pictures matched for size and brightness for VPC, while using computer-displayed BW pictures uncontrolled for size and brightness for DNMS. In light of these findings, this overlooked difference might have been largely responsible for the different outcomes of the two recognition tasks. Indeed, provided the pictures used are dissimilar, VPC leads to the same conclusion as DNMS: Recognition memory is spared by selective hippocampal lesions and color is not the determinant factor for such VPC sparing to occur as it is equally present with dissimilar BW pictures with gray shading replacing colors. This conclusion is strengthened by our recent results that animals with hippocampal lesions in the present study with spared recognition memory in VPC with dissimilar color and BW pictures also showed spared performance when subsequently tested on DNMS (Heuer and Bachevalier 2010).
By contrast, the divergent outcomes reported earlier in monkeys cannot be due to the difference in encoding time, 25-30 sec for VPC vs. 1-5 sec for DNMS. If anything, the lengthy encoding used for VPC minimized the discrepancy between the two tasks since longer familiarization facilitates, rather than impedes, VPC performance. For patient YR though, encoding time was set at 5 sec in both VPC and DNMS. It is therefore probable that this short encoding duration exacerbated the patient's VPC impairment.

By unveiling the crucial importance of stimulus discriminability, the present study considerably narrows the gap reported earlier between VPC and DNMS outcomes. It leaves, however, one residual discrepancy. Namely, for $1-5$-sec encoding, VPC performance at 30-120-sec delays was found to be impaired, despite stimuli dissimilarity. By contrast, DNMS performance at the same delays after equally brief encoding is typically spared. Thus, the possibility alluded to earlier (Nemanic et al. 2004), that incidental recognition memory is more sensitive than its intentional counterpart to hippocampal damage, cannot be totally ruled out. Alternatively, though, stimulus similarity could also explain this residual discrepancy. Indeed, pictures, however dissimilar they might be, likely remain harder to discriminate than actual objects.

\section{Role of the hippocampus in memory}

Evidence that VPC involves the hippocampus in primates is solid. It comes not only from lesion studies, but also from recording and imaging studies revealing neuronal modulations within the hippocampus predicting better VPC performance (Fried et al. 1997; Kirchoff et al. 2000; Ranganath and Rainer 2003; Rutishauser et al. 2006; Viskontas et al. 2006; Jutras et al. 2009; Jutras and Buffalo 2010). Because VPC is based on incidental novelty detection, this evidence proves that the hippocampus is involved in recognition memory even when intentional recollection is absent and in this way parallels numerous reports in both animal (Gaffan 2001; Bussey and Saksida 2005, 2007; Lee et al. 2005; Sanderson et al. 2006; Baxter 2009; Suzuki 2009; Graham et al. 2010) and human literature (Chun and Phelps 1999; Ryan et al. 2000; Greene 2007; Greene et al. 2007), indicating that the hippocampus serves a broader function than long-term recollection.

The influence of task parameters on monkeys' VPC performances could in fact inform on the processes supported by the hippocampus. The present study shows that recognition memory is spared by hippocampal lesions when (1) sufficient time is provided to encode the familiar item and (2) the novel item is sufficiently dissimilar from the familiar one. By contrast, it is impaired when familiarization is very brief, or when the familiar and novel items share overlapping features. This complements earlier reports of impaired VPC performance in monkeys with hippocampal lesions when novelty is limited to the spatial relationships between several items, or to the background of individual items (Bachevalier and Nemanic 2008; Pascalis et al. 2009; J Bachevalier, S Nemanic, and M Alvarado, unpubl.). Thus, the hippocampus seems important for incidental recognition memory only when it relies on a fine-grained comparison of familiar and novel items (for similar data in rodents, see Wan et al. 1999; Mumby et al. 2002; Hoge and Kesner 2007; Hunsaker et al. 2007; VanElzakker et al. 2008). Future work will be required to determine the specific stimulus attributes that engage the hippocampus in recognition memory-whether it is related to "ambiguous features" (Bussey and Saksida 2005, 2007), to fine-grained perceptual comparisons of stimuli present even in difficult color stimuli, or to the spatial arrangement of stimulus features (Pihlajamaki et al. 2004; Bachevalier and Nemanic 2008).

In any case, the present data fit well with current models that view the hippocampus as a comparator capable of individualizing the representations of highly overlapping inputs (Gray and 
McNaughton 2000, Vinogradova 2001, Kesner 2007; Kirwan and Stark 2007; Kumaran and Maguire 2007, 2009). This computation may be a prerequisite for intentional recollection of episodic memories (Norman and O'Reilly 2003; Sanderson et al. 2006; Eichenbaum et al. 2007), but it could also be critical for the incidental processing of novel information underlying VPC (Snyder et al. 2008), which allows an organism to rapidly and effortlessly detect changes in the environment, especially when these changes are subtle or occur rapidly.

\section{Materials and Methods}

\section{Subjects}

Six adult male rhesus monkeys (Macaca mulatta), different from the monkeys used in Nemanic et al. (2004) were used. They weighed $3.8-5.5 \mathrm{~kg}$ and ranged from 2.5 to 3.2 years old. Three of the monkeys received sham operations (Group C) and the remaining three received neurotoxic lesions of the hippocampal formation (Group H-ibo). They were housed in individual cages at the University of Texas M.D. Anderson Cancer Center Department of Veterinary Medicine and Surgery (an AAALAC accredited institution). Water was available ad libitum and a high-protein diet (Purina Monkey Chow) was given twice daily, supplemented by fresh fruits and vegetables. Lights in the room were kept on a 12:12-h light-dark cycle. All experimental procedures were approved by the Animal Care and Use Committee of the University of Texas Health Science Center, Houston, TX.

\section{Neuroimaging}

Magnetic resonance imaging (MRI) techniques (Málková et al. 2001; Nemanic et al. 2002, 2004) were used to determine the stereotaxic coordinates of ibotenic acid injection sites prior to surgery (5-7 d) and to assess lesion extent post-surgery (8-10 d).

Each animal was first sedated in their home cage $(10 \mathrm{mg} / \mathrm{kg}$ of $7: 3$ ketamine hydrochloride, $100 \mathrm{mg} / \mathrm{mL}$, and xylazine, $20 \mathrm{mg} / \mathrm{mL}$, i.m.), intubated, and anesthetized with isoflurane gas $(1.0 \%-3.0 \%, \mathrm{v} / \mathrm{v}$, to effect), and transported to the MRI facility. The animal's head was secured in a nonferromagnetic stereotaxic apparatus (Crist Instruments) and the brain was imaged with a GE Signa 1.5 Tesla Echo Speed scanner (GE Medical Systems) with a 5 in. circular surface coil. Two scanning sessions performed $1-3$ wk presurgery and $7-10 \mathrm{~d}$ post-surgery included a T1-weighted structural scan (1-mm thick) and 3 fluid attenuated inversion recovery scans (FLAIR, 3-mm-thick offset by $1-\mathrm{mm}$ posterior), both acquired in the coronal plane.

\section{Surgery}

The day of surgery, the animal was sedated (ketamine hydrochloride, $10 \mathrm{mg} / \mathrm{kg}$, i.m.), intubated, and maintained on isoflurane gas $(1.0 \%-2.0 \%, \mathrm{v} / \mathrm{v}$, to effect) for the duration of surgery. The animal was placed on a heating pad to prevent hypothermia, Emla cream was placed over the eye sockets and the ear canal to reduce eye and ear pain caused by the stereotaxic apparatus, and an ophthalmic ointment was used to prevent ocular dryness. An intravenous drip solution containing $0.45 \%$ sodium chloride was infused for hydration and the animal's heart rate, respiration rate, blood pressure, expired $\mathrm{CO}_{2}$, and body temperature were monitored throughout the procedure. The anesthetized animal was repositioned in the stereotaxic apparatus and its scalp shaved and disinfected with Nolvasan solution. Marcaine $(25 \%, 1.5 \mathrm{~mL})$, a local anesthetic, was injected along the intended incision line. Using aseptic techniques, a midline longitudinal incision was made from a midpoint on the supra-orbital ridge to the occipital notch, and the skin, connective tissue (galea) and temporalis muscles were retracted to expose the cranium. Small craniotomies were made bilaterally and the dura was incised above the injection sites.
The animals received treatments that began $12 \mathrm{~h}$ before the surgery and consisted of dexamethazone sodium phosphate $(0.4 \mathrm{mg} / \mathrm{kg}$, i.m.) and cephazolin $(25 \mathrm{mg} / \mathrm{kg}$, i.m.) as a protection against edema and infection, respectively. Both treatments were continued the day of surgery and for seven post-surgical days. Cephazolin was given four times the day of surgery and twice a day for the following $7 \mathrm{~d}$. Dexamethazone sodium phosphate was given four times a day, with progressive withdrawal of the drug for the following 3-4 d. Acetaminophen $(10 \mathrm{mg} / \mathrm{kg}$, p.o.) was given four times a day for $3 \mathrm{~d}$ after surgery for pain relief.

\section{Neurotoxic hippocampal lesions}

Hippocampal lesions were intended to damage all of the ammonic fields, the prosubiculum and subiculum (see Fig. 2, left column). Using the animals' individual pre-surgical T1-weighted MR images, the number of injection sites and their positions in the anterior/posterior, medial/lateral, and dorsal/ventral planes were calculated. For the anterior portion of the hippocampal formation, where the uncus was clearly visible, two injection sites were selected bilaterally every $1.5 \mathrm{~mm}$, with one more lateral to target the body of the hippocampal formation and one more medial to target the uncus. For the posterior $2 / 3$, one injection site was selected every $1.5 \mathrm{~mm}$ and was centered within the body of the hippocampal formation. MRI coordinates of each injection site were then transformed into stereotaxic coordinates prior to surgery. For each animal, there were 10 injection sites selected on each side. Case H-ibo-7 underwent a second surgery 2 mo after the first one because the post-surgical FLAIR images obtained after the first surgery revealed almost no hypersignals in the left hippocampus, indicating little evidence of cell death in this area. Thus, the coordinates of the spared hippocampal tissue were recorded and used to inject ibotenic acid during a second surgical procedure.

The needle of a 10- $\mu \mathrm{L}$ Hamilton syringe held by a Kopf electrode manipulator (David Kopf Instruments, Tujunga, CA) was lowered at each injection site where 1.5 or $2.4 \mu \mathrm{L}$ ibotenic acid (Biosearch Technologies, Novato, CA, $10 \mathrm{mg} / \mathrm{mL}$ in PBS, pH 7.4) was injected at a rate of $0.4 \mu \mathrm{L} / \mathrm{min}$. Both hemispheres were injected simultaneously and after the completion of each injection, the needle remained in place for three minutes to allow the neurotoxin to diffuse and to minimize any potential for it to spread up the needle track during retraction.

\section{Sham lesions}

After opening the skin, bilateral craniotomies were made as described above. The dura was cut bilaterally, but no needle penetrations were made.

\section{Evaluation of lesion extent}

Evaluations of the extent of damage in Group H-ibo were performed using MRI techniques for all three cases (Málková et al. 2001; Nemanic et al. 2002) and histological procedures for case H-ibo-9. Briefly, MRI-based evaluation was performed using hypersignals observed on the post-surgical FLAIR coronal images of each animal. The hypersignals indicate edema that arises from cell death caused by the neurotoxin injection. For histological processing, at the end of all behavioral testing, case $\mathrm{H}$-ibo-9 was sedated with ketamine $\mathrm{HCl}(10 \mathrm{mg} / \mathrm{kg}$, IM) and given a lethal dose of sodium pentobarbital (25-30 $\mathrm{mg} / \mathrm{kg}$ IV or IM). The animal was perfused transcardially first with $0.9 \%$ buffered saline, then $4.0 \%$ paraformaldehyde, followed by $5 \%$ and then $10 \%$ glycerol. The brain was removed and transferred through $10 \%$ glycerol with $4 \%$ paraformaldehyde, $10 \%$ glycerol with $0.1 \mathrm{M}$ phosphate buffer, and, finally, 20\% glycerol with $0.1 \mathrm{M}$ phosphate buffer at $4^{\circ} \mathrm{C}$. The brain was then frozen, cut into $50 \mu \mathrm{m}$ sections in the coronal plane, and every sixth section was mounted and stained with thionin to visualize cell bodies.

The extent of hypersignals identified on coronal MR images or cell loss identified on coronal histological sections was 
drawn onto matched coronal sections of the template brain at 1-mm intervals using Adobe Photoshop software (v. 6). ImageJ (http://rsb.info.nih.gov/ij/) was then used to measure the surface area (in square pixels) of damage to the left and right hippocampal formation (including all CA fields, dentate gyrus, and subicular complex) on each coronal section, as well as any extra damage to adjacent neural structures (i.e., entorhinal and perirhinal cortex, areas TH and TF on the parahippocampal gyrus and amygdala). For each structure, the total volume of damage was calculated by summing the surface area of damage on each section through each hemisphere and then multiplying by image thickness (1 mm) (Gundersen and Jensen 1987). Percent volume damaged was then calculated by dividing volume of damage by normal volume and multiplying by 100 .

\section{Behavioral procedures}

All animals in both groups received the same behavioral training and were all behaviorally naïve when testing on the VPC task began 2 mo after surgery.

\section{Apparatus}

The monkey was seated in a Plexiglas primate chair (Crist Instruments) approximately $40 \mathrm{~cm}$ in front of a 19-in. highresolution computer monitor. The images were sent to the monitor via a computer controlled by the experimenter. A video camera (Sony Digital8 TRV-140), mounted above the computer monitor, was positioned so that the eyes of the monkey were clearly visible and their movements could be recorded. The camera output was fed into a time/date generator connected to a VCR (JVC HR-S4800U) and then into a TV monitor to allow the experimenter to observe the animal's looking behavior during the task. The room was equipped with a white noise generator to reduce external noise. The animals were neither food deprived nor water restricted and remained in the chair for no more than $45 \min$ a day.

\section{Testing procedure}

The monkeys were trained for $1 \mathrm{wk}$ to sit quietly in the testing room while passively viewing stimuli presented on the computer monitor, following which formal testing began. Each VPC trial began with a familiarization phase in which a sample stimulus appeared in the center of the monitor. The experimenter monitored the time the monkey actually spent looking at the stimulus and interrupted the familiarization phase when the predetermined amount of exposure was achieved (encoding duration). After a variable retention delay, the sample stimulus and a new one were displayed side-by-side on the monitor for two retention tests, lasting $5 \mathrm{sec}$ each and separated by a 5 -sec interval. The left/right position of the novel image during the first retention test varied pseudorandomly across trials and was reversed during the second retention test. The animals were given four to 10 trials per day. They did not receive food treats during testing.

\section{Stimuli}

As stimulus pairs were trial-unique (i.e., never repeated within a condition or across conditions), a total of 360 digitized clipart pictures of variegated objects, trees, animals, tools, etc. were gathered to form 180 pairs and allow to test as many trials. For the majority of pairs (150), the two objects composing the pair were intentionally selected to be as distinct as possible, and their pictures to be easily discriminable whether their original colored version was retained (dissimilar color stimuli) or replaced by a "black and white" version transforming colors into shades of gray (dissimilar BW stimuli). The remaining 30 pairs were opposite, they were intentionally composed of related objects sharing many overlapping features (two planes, two tables, two chairs, two dogs, etc), and their pictures were presented in their BW version to further impede stimuli discriminability (dissimilar stimuli). Note that, among the three stimulus types, the dissimilar BW stimuli were digitized pictures of objects used in earlier studies (e.g., Nemanic et al. 2004). As earlier, BW pictures were equated for size and brightness; the difference, however, was that more attention was paid to keep the objects composing each pair as distinct as possible. Figure 1 provides two examples of stimulus pairs for each of the three types of stimulus. Each picture appeared on the black background of the display screen as a white $14 \times$ $12 \mathrm{~cm}$ rectangle framing a central object. During familiarization, the picture of the sample object was centered on the computer monitor. During retention tests, the picture of the sample and novel objects were presented on the right and left sides of the monitor, separated by $10 \mathrm{~cm}$.

\section{Novelty preference for dissimilar color vs. BW stimuli}

As a first step, we tested whether improving stimulus discriminability to a level close to that provided by the 3D objects used in DNMS would suppress VPC deficits after hippocampal lesions, and, if so, whether color was essential for this recognition memory sparing to occur. To this aim, monkeys were tested first with 30 pairs of dissimilar color stimuli, and then with 30 pairs of dissimilar BW stimuli. The duration of encoding was kept constant at 30 sec. Three retention delays $(10,60$, and $120 \mathrm{sec})$ were intermixed in a pseudorandom order for each stimulus type. Each animal's performance was thus evaluated for a total of 10 trials per delay and stimulus type.

\section{Novelty preference for dissimilar vs. similar stimuli}

To assess whether VPC performance after hippocampal lesions deteriorates when stimulus discriminability increases, monkeys were then tested with 30 additional pairs composed of similar stimuli. The same encoding duration $(30 \mathrm{sec})$ was used, and the same retention delays $(10,60$, and $120 \mathrm{sec})$ were intermixed across trials, again for a total of 10 trials per delay.

\section{Novelty preference after reduced encoding duration}

The final step was to explore novelty preference when exposure to the sample stimulus was reduced. Monkeys were first tested with an encoding time of $10 \mathrm{sec}$, instead of the 30-sec duration used in an earlier study (Nemanic et al. 2004). Thirty trials were carried out using five color and five BW dissimilar stimuli per delay. The two stimulus types (color and BW) and three delays (30, 60, and $120 \mathrm{sec}$ ) were intermixed pseudorandomly across trials. Then, encoding time was further reduced, to 5 and $1 \mathrm{sec}$, i.e., to durations approximating those typically occurring in DNMS. A total of 60 more trials were carried out using five color and five BW dissimilar stimuli per delay and encoding duration. The two stimulus types, two encoding durations, and three delays were intermixed pseudorandomly across trials. Similar stimuli were not tested with reduced encoding duration.

\section{Data analysis}

Two observers, each blind to the lesion group of the subject, scored the videotapes independently (interobserver reliability: Pearson $r=0.92)$. For each trial, they performed a frame-by-frame analysis of the videotapes to calculate (Pascalis and Bachevalier 1999): (1) the time needed to accumulate the required encoding duration during the familiarization phase, (2) the time actually spent looking at the stimuli during the retention tests, and (3) the percent looking at the novel stimulus across the two retention tests ([time looking at novel/total looking time] $\times 100$ ). Statistical comparisons were carried out using the SYSTAT 13 software. ANOVAs were used to analyze the effect of group (H-ibo vs. controls), and repeated measures and a Huynh-Feldt correction were performed to assess the effects of stimulus type, encoding duration and delay. One-sided, two-sample or one-sample, $t$-tests were used to conduct planned comparisons (Pedhazur 1982) between groups and to analyze whether performance differed from chance, respectively. 


\section{Acknowledgments}

This work was supported by grants from the National Institute of Mental Health (MH-58846), National Institute of Child Health and Human Development (HD-35471), Yerkes (Base Grant No. NIH RR00165), Center for Behavioral Neuroscience (Grant No. NSF IBN-9876754), and the CNRS. We thank the University of Texas Health Science Center at Houston veterinary and animal husbandry staff for expert animal care, Roger E. Price and Belinda Rivera for the care and handling of animals during the MR imaging procedures, Edward F. Jackson for assistance in neuroimaging techniques, and Christa Payne and Maria Alvarado for help with histological processing of the brains.

\section{References}

Ainge JA, Heron-Maxwell C, Theofilas P, Wright P, de Hoz L, Wood ER. 2006. The role of the hippocampus in object recognition in rats: Examination of the influence of task parameters and lesion size. Behav Brain Res 167: 183-195.

Alvarado M, Kazama A, Zeamer A, Bachevalier J. 2010. The effects of selective hippocampal damage on tests of oddity in rhesus macaques. Hippocampus doi: 10.1002/hipo.20827.

Bachevalier J, Meunier M. 1996. Cerebral ischemia: Are the memory deficits associated with hippocampal cell loss? Hippocampus 6: 553-560.

Bachevalier J, Nemanic S. 2008. Spatial memory in monkeys as measured with the visual paired-comparison task: Effects of selective hippocampal, perirhinal and areas TH/TF lesions. Hippocampus 18: 64-80.

Bakker A, Kirwan CB, Miller M, Stark CEL. 2008. Pattern separation in the human hippocampal CA3 and dentate gyrus. Science 319: 1640-1642.

Baxter MG. 2009. Involvement of medial temporal lobe structures in memory and perception. Neuron 61: 667-677.

Baxter MG, Murray EA. 2001. Opposite relationship of hippocampal and rhinal cortex damage to delayed nonmatching-to-sample deficits in monkeys. Hippocampus 11: 61-71.

Beason-Held LL, Rosene DL, Killiany RJ, Moss MB. 1999. Hippocampal formation lesions produce memory impairment in the Rhesus monkey. Hippocampus 9: 562-574.

Brennan WN, Ames EW, Moore RW. 1966. Age differences in infants attention to patterns of different complexities. Science 151: 354-356.

Bussey TJ, Saksida LM. 2005. Object memory and perception in the medial temporal lobe: An alternative approach. Cur Opin Neurobiol 15: $730-737$

Bussey TJ, Saksida LM. 2007. Memory, perception and the ventral visual-perirhinal-hippocampal stream: Thinking outside of the boxes. Hippocampus 17: 898-908.

Chun MM, Phelps EA. 1999. Memory deficits for implicit contextual information in amnesic subjects with hippocampal damage. Nat Neurosci 2: 844-847.

Colombo J, Mitchell DW, Horowitz FD. 1988. Infant visual attention in the paired-comparison paradigm: Test-retest and attention-performance relations. Child Dev 59: 1198-1210.

Eichenbaum H, Yonelinas AP, Ranganath C. 2007. The medial temporal lobe and recognition memory. Annu Rev Neurosci 30: 123-152.

Fagan JF. 1974. Infant recognition memory: The effects of length of familiarization and type of discrimination task. Child Dev 45: 351-356.

Fantz RL, Fagan JF, Miranda S. 1975. Early visual selectivity. In Infant perception: From sensation to cognition, Vol. 2 (ed. LB Cohen, P Salapatek), pp. 249-341. Academic, New York.

Fried I, MacDonald KA, Wilson CL. 1997. Single neuron activity in human hippocampus and amygdala during recognition of faces and objects. Neuron 18: $753-765$.

Gaffan D. 2001. What is a memory system? Horel's critique revisited. Behav Brain Res 127: 5-11.

Graham KS, Barense MD, Lee ACH. 2010. Going beyond LTM in MTL: A synthesis of neuropsychological and neuroimaging findings on the role of the medial temporal lobe in memory and perception. Neuropsychologia 48: 831-853.

Gray JA, McNaughton N. 2000. The neuropsychology of anxiety, 2nd ed. Oxford University Press, Oxford, UK.

Greene AJ. 2007. Human hippocampal-dependent tasks: Is awareness necessary or sufficient? Hippocampus 17: 429-433.

Greene AJ, Gross WL, Elsinger CL, Rao SM. 2007. Hippocampal differentiation without recognition: An fMRI analysis of the contextual cueing task. Learn Mem 14: 548-553.

Gundersen HJ, Jensen EB. 1987. The efficiency of systematic sampling in stereology and its prediction. J Microsc 147: 229-263.
Gunderson VM, Swartz KB. 1986. Effects of familiarization time on visual recognition memory in infant pigtailed macaques (Macaca nemestrina). Develop Psychol 22: $477-480$.

Heuer E, Bachevalier J. 2011. Effects of selective neonatal hippocampal lesions on tests of object and spatial recognition memory in monkeys. Behav Neurosci (in press).

Hoge J, Kesner RP. 2007. Role of CA3 and CA1 subregions of the dorsal hippocampus on temporal processing of objects. Neurobiol Learn Mem 88: $225-231$

Holdstock JS, Mayes AR, Roberts N, Cezayirli E, Isaac CL, O'Reilly RC, Norman KA. 2002. Under what conditions is recognition spared relative to recall after selective hippocampal damage in humans? Hippocampus 12: 341-351.

Hunsaker MR, Mooy GG, Swift JS, Kesner RP. 2007. Dissociations of the medial and lateral perforant path projections into dorsal DG, CA3, and CA1 for spatial and nonspatial (visual object) information processing. Behav Neurosci 121: 742-750.

Hunter MA, Ross HS, Ames EW. 1982. Preferences for familiar or novel toys: Effects of familiarization time in one-year-olds. Develop Psychol 18: $519-529$.

Hunter MA, Ames EW, Koopman R. 1983. Effects of stimulus complexity and familiarization time on infant preferences for novel and familiar stimuli. Develop Psychol 19: 338-352.

Jutras MJ, Buffalo EA. 2010. Recognition memory signals in the macaque hippocampus. PNAS 107: 401-406.

Jutras MJ, Fries P, Buffalo EA. 2009. Gamma-band synchronization in the macaque hippocampus and memory formation. J Neurosci 29: $12521-12531$

Karmel BZ. 1969. The effects of age, complexity, and amount of contour on pattern preferences in human infants. J Exp Child Psychol 7: $339-354$.

Kesner RP. 2007. Behavioral functions of the CA3 subregion of the hippocampus. Learn Mem 14: 771-781.

Kirchoff BA, Wagner AD, Maril A, Stern CE. 2000. Prefrontal-temporal circuitry for episodic encoding and subsequent memory. J Neurosci 20: 6173-6180.

Kirwan CB, Stark CEL. 2007. Overcoming interference: An fMRI investigation of pattern separation in the medial temporal lobe. Learn Mem 14: 625-633.

Kumaran D, Maguire EA. 2007. Which computational mechanisms operate in the hippocampus during novelty detection? Hippocampus 17: $735-748$.

Kumaran D, Maguire EA. 2009. Novelty signals: A window into hippocampal information processing. TICS 13: 47-54.

Lee ACH, Bussey TJ, Murray EA, Saksida LM, Epstein RA, Kapur N, Hodges JR, Graham KS. 2005. Perceptual deficits in amnesia: Challenging the medial temporal lobe 'mnemonic' view. Neuropsychologia 43: 1-11.

Málková L, Lex CK, Mishkin M, Saunders RC. 2001. MRI-based evaluation of locus and extent of neurotoxic lesions in monkeys. Hippocampus 11: $361-370$

Mumby DG, Wood ER, Duva CA, Kornecook TJ, Pinel JP, Phillips AG. 1996. Ischemia-induced object-recognition deficits in rats are attenuated by hippocampal ablation before or soon after ischemia. Behav Neurosci 110: $266-281$.

Mumby DG, Gaskin S, Glenn MJ, Schramek TE, Lehmann H. 2002. Hippocampal damage and exploratory preferences in rats: Memory for objects, places, and contexts. Learn Mem 9: 47-57.

Murray EA, Mishkin M. 1998. Object recognition and location memory in monkeys with excitotoxic lesions of the amygdala and hippocampus. $J$ Neurosci 18: 6568-6582.

Nemanic S, Alvarado MC, Price RE, Jackson EF, Bachevalier J. 2002. Assessment of locus and extent of neurotoxic lesions in monkeys using neuroimaging techniques: A replication. J Neurosci Methods 121: 199-209.

Nemanic S, Alvarado MC, Bachevalier J. 2004. The hippocampal/ parahippocampal regions and recognition memory: Insights from visual paired comparison versus object-delayed nonmatching in monkeys. I Neurosci 24: 2013-2026.

Norman KA, O'Reilly RC. 2003. Modeling hippocampal and neocortical contributions to recognition memory: A complementary-learningsystems approach. Psychol Rev 110: 611-646.

Pascalis O, Bachevalier J. 1999. Neonatal aspiration lesions of the hippocampal formation impair visual recognition memory when assessed by paired-comparison task but not by delayed nonmatching-to-sample task. Hippocampus 9: 609-616.

Pascalis O, Hunkin NM, Holdstock JS, Isaac CL, Mayes AR. 2004. Visual paired comparison performance is impaired in a patient with selective hippocampal lesions and relatively intact item recognition. Neuropsychologia 42: 1293-1300.

Pascalis O, Hunkin NM, Bachevalier J, Mayes AR. 2009. Change in background context disrupts performance on visual paired comparison following hippocampal damage. Neuropsychologia 47: 2107-2113. 
Pedhazur EJ. 1982. Multiple regression in behavioral research: Explanation and prediction, 2nd ed. Holt, Rinehart and Winston, New York.

Pihlajamaki M, Tanila H, Kononen M, Hanninen T, Hamalainen A, Soininen H, Aronen HJ. 2004. Visual presentation of novel objects and new spatial arrangements of objects differentially activates the medial temporal lobe subareas in humans. Eur J Neurosci 19: 1939-1949.

Ranganath C, Rainer G. 2003. Neural mechanisms for detecting and remembering novel events. Nat Neurosci 4: 193-202.

Richards JE. 1997. Effects of attention on infants' preference for briefly exposed stimuli in the paired-comparison recognition-memory paradigm. Develop Psychol 33: 22-31.

Richmond J, Sowerby P, Colombo M, Hayne H. 2004. The effect of familiarization time, retention interval, and context change on adults' performance in the visual paired-comparison task. Dev Psychobiol 44: $146-155$.

Rose SA. 1983. Differential rates of visual information processing in fullterm and preterm infants. Child Dev 54: 1189-1198.

Rose SA, Gottfried AW, Melloy-Carminar PM, Bridger WH. 1982 Familiarity and novelty preferences in infant recognition memory: Implications for information processing. Develop Psychol 18: 704-713.

Rutishauser U, Mamelak AN, Schuman EN. 2006. Single-trial learning of novel stimuli by individual neurons of the human hippocampus-amygdala complex. Neuron 49: 805-813.

Ryan JD, Althoff RR, Whitlow W, Cohen NJ. 2000. Amnesia is a deficit in relational memory. Psychol Sci 11: 454-461.

Sanderson DJ, Pearce JM, Kyd RJ, Aggleton JP. 2006. The importance of the rat hippocampus for learning the structure of visual arrays. Eur $J$ Neurosci 24: $1781-1788$.

Seress L, Abraham H. 2008. Pre- and post-natal morphological development of the human hippocampal formation. In Handbook of developmental cognitive neuroscience, 2nd ed. (ed. CA Nelson, M Luciana), pp. 187-211. The MIT Press, Cambridge, MA.

Snyder KA, Blank MP, Marsolek CJ. 2008. What form of memory underlies novelty preferences? Psychonomic Bull Rev 15: 315-321.

Suzuki WA. 2009. Perception and the medial temporal lobe: Evaluating the current evidence. Neuron 61: 657-666.

VanElzakker M, Fevurly RD, Breindel T, Spencer RL. 2008. Environmental novelty is associated with a selective increase in Fos expression in the output elements of the hippocampal formation and the perirhinal cortex. Learn Mem 15: 899-908.

Vinogradova OS. 2001. Hippocampus as comparator: Role of the two input and two output systems of the hippocampus in selection and registration of information. Hippocampus 11: 578-598.

Viskontas IV, Knowlton BJ, Steinmetz PN, Fried I. 2006. Differences in mnemonic processing by neurons in the human hippocampus and parahippocampal regions. J Cogn Neurosci 18: 1654-1662.

von Bonin G, Bailey P. 1947. The neocortex of Macaca mulatta. University of Illinois Press, Urbana, IL.

Wan H, Aggleton JP, Brown MW. 1999. Different contributions of the hippocampus and perirhinal cortex to recognition memory. J Neurosci 19: $1142-1148$

Zeamer AE, Heuer E, Bachevalier J. 2010. Developmental trajectory of object recognition memory in infant rhesus monkeys with and without neonatal hippocampal lesions. J Neurosci 30: 9157-9165.

Zola SM, Squire LR, Teng E, Stefanacci L, Buffalo EA, Clark RE. 2000. Impaired recognition memory in monkeys after damage limited to the hippocampal region. J Neurosci 20: 451-463.

Received November 9, 2010; accepted in revised form December 28, 2010. 


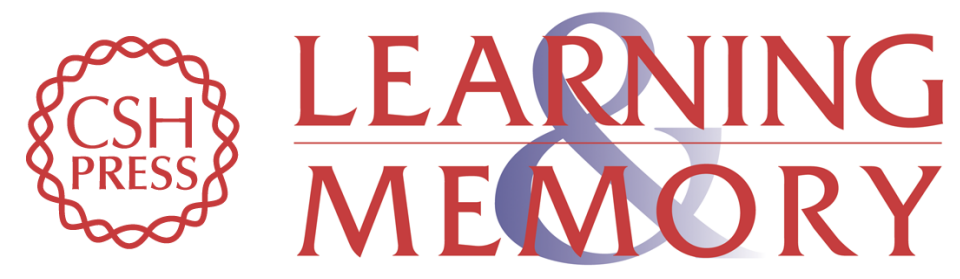

\section{Stimulus similarity and encoding time influence incidental recognition memory in adult monkeys with selective hippocampal lesions}

Alyson Zeamer, Martine Meunier and Jocelyne Bachevalier

Learn. Mem. 2011, 18:

Access the most recent version at doi: $10.1101 / \mathrm{lm} .2076811$

References This article cites 63 articles, 14 of which can be accessed free at: http://learnmem.cshlp.org/content/18/3/170.full.html\#ref-list-1

License

Email Alerting Receive free email alerts when new articles cite this article - sign up in the box at the Service top right corner of the article or click here. 